\title{
AN INTERESTING EXAMPLE OF PINGUICULA MACROCERAS FROM VANCOUVER ISLAND, CANADA
}

Chad KreutZenstein •Victoria • British Columbia • Canada • smilodonichthys@protonmail.com JUSTIN DUNNING • Victoria • British Columbia • Canada • canadiancarnivorousplants@gmail.com

Having found many populations of what is known as Pinguicula macroceras on Vancouver Island, we have noticed this species can vary greatly in morphology between locations. One interesting example of this is from plants found along the Gordon River on the southwest coast of the island near the town of Port Renfrew.

The habitat of the Gordon River population is notable in that it is found in seeps in proximity to karst (Fig. 1A, photo taken from cave overlooking the river). One of the seeps they are growing on originates from a spring flowing from a cliff of the river canyon at the transition between limestone and igneous rock. The other seeps in the area originate from groundwater flowing through forest soil above the canyon (Fig. 1B, typical groundwater seeps seen on the right). It is not obvious in these examples whether they have karstic influence. Given how much limestone is in the area there is a good chance they are. We have not observed any of these plants growing directly on the limestone.

What we noticed, is these plants can produce up to 6 inflorescences when fully mature (Fig. 2A) and often have 2-5. From looking into the literature, this appears to be unusual for this species. The usual number seems to be between 1-3 with a maximum of 5 .

Another unusual characteristic of this population is the sometimes reduced but usually completely absent white patch on the lower corolla lobes. Often any white colouration is only present on the tips of the trichomes of the "pseudopollen lure" near the entrance of the corolla tube (Figs. 2 B \& C).

Many of the P. macroceras from this population and the surrounding area exhibit stamen-like structures protruding from under the calyx. These structures have the angled look of insect legs (Fig. 2D) In our research, we cannot find anything describing these characteristics on other populations.

Seed collected from this location grew into plants with the same lack of a white corolla patch and propensity to be unusually floriferous (Fig. 3). None seem to be mature enough to produce more than 4 inflorescences yet, though.
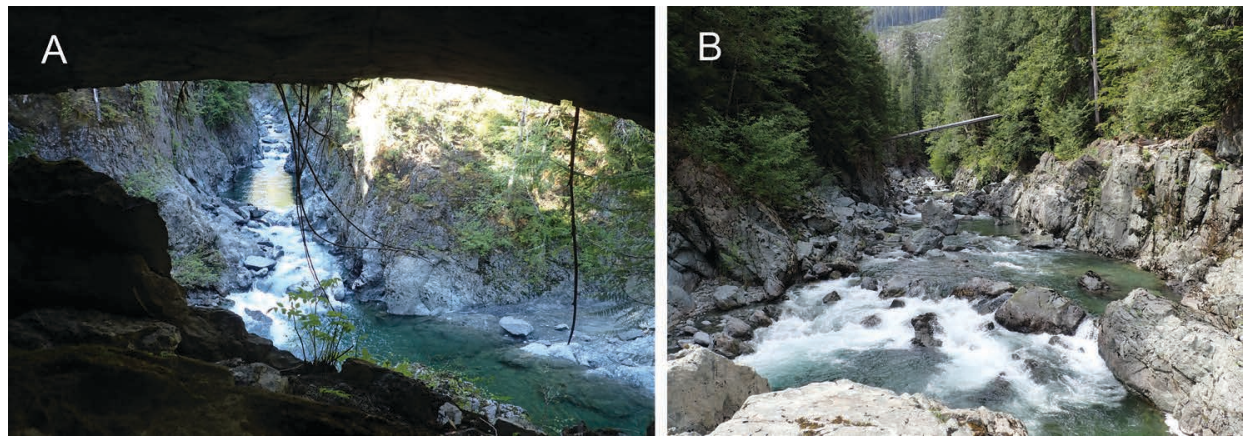

Figure 1: A) Photo taken from cave in karst overlooking the Gordon River; B) springs flowing from a cliff on the right side of the river canyon at the transition between limestone and igneous rock. 

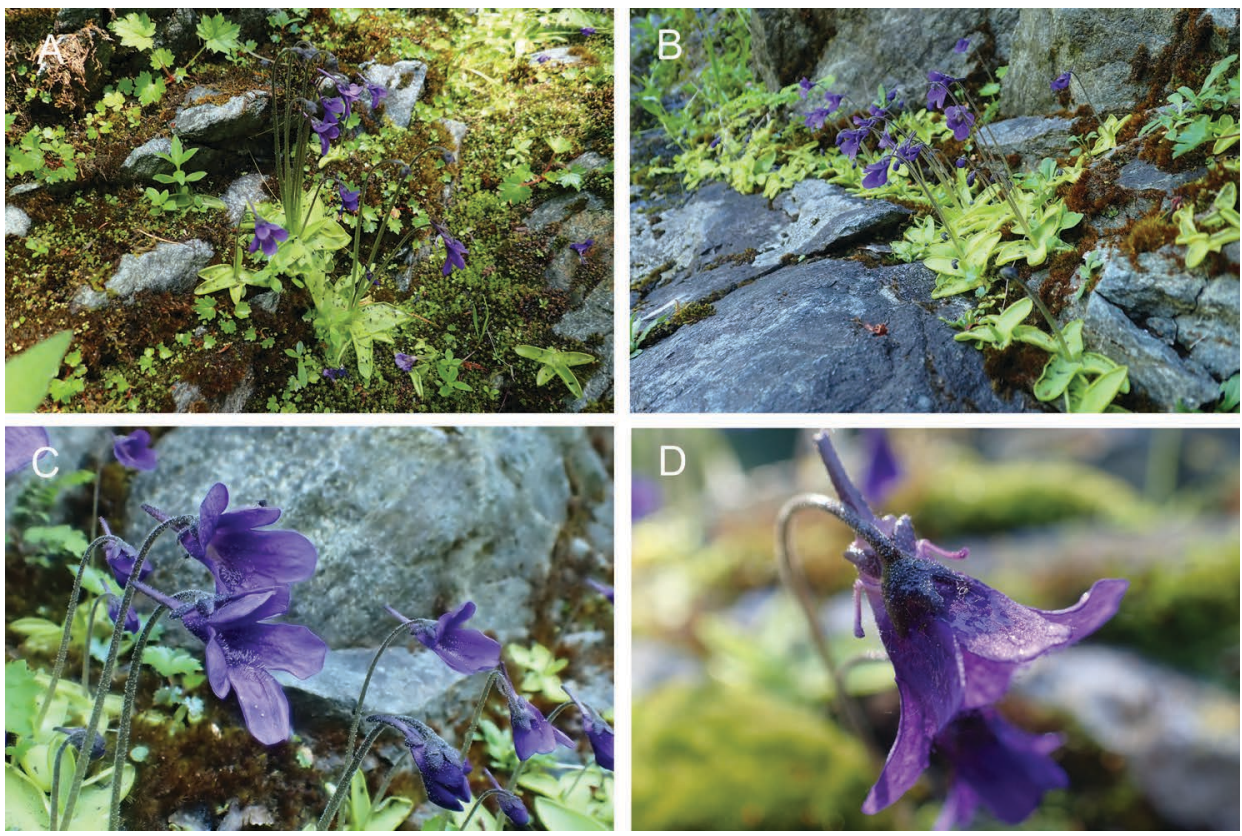

Figure 2: A) Pinguicula macroceras producing up to 6 inflorescences; B \& C) inflorescences are usually completely absent a white patch on the lower corolla lobes; any white colouration is only present on the tips of the trichomes of the "pseudopollen lure" near the entrance of the corolla tube; D) stamen-like structures protruding from under the calyx have the angled look of insect legs.

We will continue to explore the diversity of $P$. macroceras on Vancouver Island and hope to compile our observations into a longer article. This is a look at a single population, but we have found notable examples of the diversity of this taxon at many other locations on Vancouver Island.
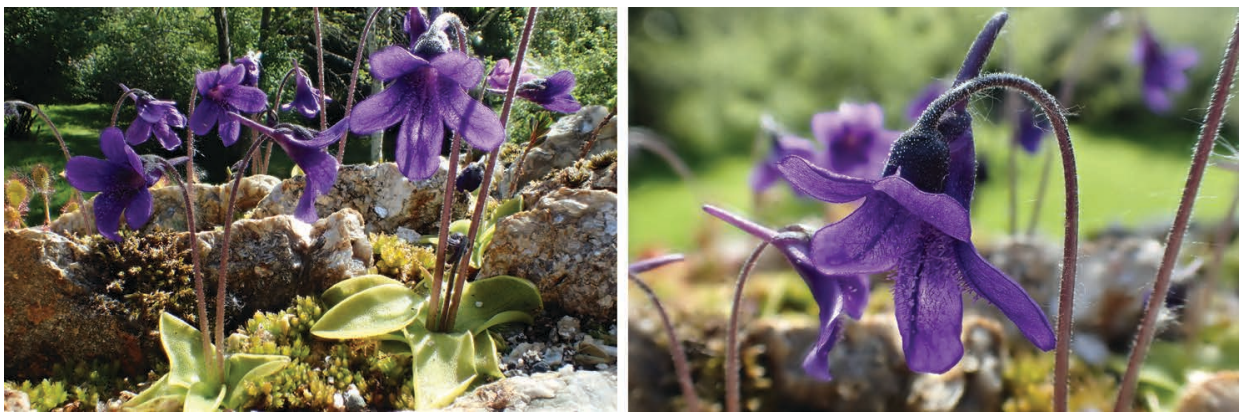

Figure 3: Pinguicula macroceras from seed collected from plants growing in seeps in proximity of karst. 